Caligrama, Belo Horizonte, v. 23, n. 3, p. 25-46, 2018

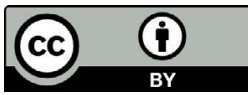

\title{
Garcilaso de la Vega y Guaman Poma de Ayala en El pez de oro de Gamaliel Churata: noticia de una polémica
}

\author{
Garcilaso de la Vega and Guaman Poma de Ayala \\ in EI Pez de Oro by Gamaliel Churata: Report of a Controversy
}

\author{
Meritxell Hernando Marsal \\ Universidade Federal de Santa Catarina (UFSC), Florianópolis, Santa Catarina / Brasil \\ meritxellhmarsal@gmail.com
}

Resumen: La obra del escritor peruano Gamaliel Churata es adoptada por la crítica literaria postcolonial latinoamericana como un modelo productivo, que anticipa y pone en práctica sus observaciones. Su trabajo se nutre de textos anteriores, especialmente de los cronistas de la época colonial, Garcilaso de la Vega y Guaman Poma de Ayala. En ellos, el gesto de resistencia a la imposición colonial está tempranamente registrado y Churata lo rescata y activa en su obra. De esta manera, lo colonial, en el límite de lo dicho, y lo postcolonial, se encuentran en una relación activa. Ahora bien, estos dos cronistas constituyen una dicotomía conflictiva en la primera parte de El pez de oro, que identifica uno con la conformidad al sistema y el otro con su subversión. En el presente trabajo serán analizados los términos de esta polémica para resaltar cómo Churata se enfrenta a la crítica literaria hispanizante y a sus lecturas, desautorizando la preeminencia de Garcilaso, pero evita al mismo tiempo simplificaciones, y valora y asume a los dos cronistas como modelos de un proyecto de descolonización cultural, en que lo indígena deviene un paradigma de conocimiento y de vida.

Palabras clave: crítica postcolonial; Gamaliel Churata; Inca Garcilaso de la Vega; Guaman Poma de Ayala.

Abstract: The Peruvian writer Gamaliel Churata is adopted by Latin American postcolonial literary criticism as a productive model, which anticipates and puts into practice its thoughts. His work is nourished by previous texts, especially the chroniclers of the Colonial Era, Garcilaso de la Vega and Guaman Poma de Ayala. From them, 
Churata rescues and activates the gesture of resistance to the colonial imposition. This way, the colonial, in the limit of what could be said, and the postcolonial, are in an active relationship. However, in the first part of El Pez de Oro Churata establishes a conflicting dichotomy between these two chroniclers, which identifies one of them with conformity to the system and the other with its subversion. In the present essay, the terms of this controversy will be analyzed to highlight how Churata confronts Hispanic literary criticism and its readings, disavows Garcilaso's pre-eminence, but at the same time avoids simplification, and assumes the two chroniclers as models of a project of cultural decolonization, in which the indigenous becomes a paradigm of knowledge and life.

Keywords: postcolonial criticism; Gamaliel Churata; Inca Garcilaso de la Vega; Guaman Poma de Ayala.

El objetivo de este ensayo es reflexionar sobre la relación que se establece en la obra de Gamaliel Churata, especialmente en El pez de oro (1957), con los cronistas coloniales Garcilaso de la Vega y Guaman Poma de Ayala. En el trato de los dos cronistas puede observarse la tensión entre el propósito anticolonial de Churata, que procuraba la integración social y cultural de lo indígena en pie de igualdad con lo hispánico, y la crítica hispanizante del momento, que proponía al Inca Garcilaso de la Vega como modelo de escritor nacional. Gamaliel Churata no se conforma con la exaltación de Garcilaso, porque apaga, siguiendo la lógica colonial, la presencia cultural indígena. De esta manera, Churata cuestiona tempranamente la crítica literaria hispanoamericana, porque descarta de sus consideraciones a las lenguas indígenas y asume para la cultura una lógica colonial de exclusión. En ese sentido, su proyecto literario es valorado por la crítica postcolonial reciente, que lo toma como modelo. En la presentación a su libro Churata Postcolonial, Mabel Moraña (2015, p. 15) explicita esta intención: "Hay autores que parecen haber nacido para confirmar modelos interpretativos, para nutrirlos, refinarlos y corroborar sus fundamentos. Ese es el perfil de Churata respecto a la teoría postcolonial".

Sin embargo, Churata no simplifica la cuestión, proponiendo un rechazo absoluto a la figura y la obra de Garcilaso de la Vega. Tanto su crónica, como la de Guaman Poma, dentro de los límites impuestos por la retórica colonial, constituyen modelos y fuentes de información para sus propósitos. En El pez de oro pueden rastrearse procedimientos y motivos 
culturales tomados de ambos cronistas que contribuyen al proyecto de Churata de subrayar la vitalidad de las culturas andinas. De esta manera, las crónicas coloniales entran en relación con el cuestionamiento de la contemporaneidad y su sistema cultural, que puede nombrarse como postcolonial, porque, a pesar de los modelos políticos adoptados, no ha dejado atrás las lógicas (sociales, culturales, literarias) de la exclusión.

Para mostrar todo ello, primero voy a exponer la polémica que el autor elabora en las primeras páginas de la obra. Seguidamente, van a ser expuestos tres de los temas principales que Churata asimila de ambos cronistas para construir su crítica al conformismo cultural republicano, heredero de la colonia: la cuestión de la lengua, el mestizaje y la crítica al sistema colonial. Con el desarrollo de estos temas debe quedar clara la lectura que Churata hace de los textos coloniales rescatando su potencial subversivo para cuestionar la definición de la literatura americana y el imaginario social que configura.

\section{La polémica}

Uno de los propósitos principales de El pez de oro es relatar la cultura andina en sus prácticas (los oficios del laika, la presencia de la coca, la experiencia de los sueños), formas expresivas (sus lenguas, las canciones y las danzas), símbolos (como el pez, el puma o la sirena) y filosofía (la concepción del alma, los muertos, la colectividad) y para ello los cronistas constituyen una valiosa fuente de información, como señaló Helena Usandizaga (2012, p. 20): “conoce una serie de textos de cronistas y religiosos - españoles, mestizos e indígenas -, y menciona sobre todo a aquellos que interactuaron con la cultura autóctona (Blas Valera, el Inca Garcilaso de la Vega, Guamán Poma de Ayala...)”.

Sin embargo, a pesar de esta inspiración común, en la sección inaugural de El pez de oro, titulada "Homilía del Khori-Challwa", Churata parece censurar a Garcilaso y oponerlo a Guaman Poma. Paola Mancosu (2017, p. 458) subraya en este punto el viraje del autor: "Es, entonces, sólo en El pez de oro, que la perspectiva churatiana sobre el Inca cambia radicalmente a favor de la opción considerada más representativa de la voz americana, es decir, la de Guamán Poma”. ¿Cuál es el motivo de esta buscada fricción? Veremos que se trata nada menos que de la definición de la literatura americana. 
Churata comienza la "Homilía del Khori-Challwa" discutiendo el asunto que define su propuesta literaria: la lengua. Dice Churata que los americanos poseen sus formas artísticas, filosóficas, jurídicas y científicas contenidas en los idiomas vernáculos que, sin embargo, no tuvieron expresión escrita. Para tenerla se valieron de una lengua prestada, la hispana, y "en ella borroneamos 'como indios', aunque no en indio, que es cosa distinta" (CHURATA, 2012, p. 153). Desde aquí, Churata hace referencia a la obra del Inca Garcilaso que en sus "Advertencias acerca de la lengua general de los indios" declara escribir "como indio" (GARCILASO DE LA VEGA, 1991, p. 5) para que las palabras de su lengua sean transmitidas correctamente. Pero para escribir "como indio" para Churata (2012, p. 153) es necesario intervenir en el castellano adoptado: "hacer del español - solución provisional y aleatoria - lo que el español hizo de nosotros: mestizos". La enunciación es radical porque transfiere a la lengua el proceso histórico de la conquista y su violencia. Lo que le interesa a Churata es resaltar que la lengua de América no puede ser apenas un castellano trasplantado, sino la aleación de las lenguas en contacto: "porque un idioma colonizador no sólo impondrá sus raíces y sus modos, sino, al mismo tiempo, asimilará parte del legado que le brindan sus colonias, y aquí resulta, como ya se ha dicho, que el conquistador acaba conquistado" (CHURATA, 2017, p. 183). El lenguaje deviene, pues, un medio de subvertir la imposición colonial.

De esta manera Churata define la práctica lingüística que lleva a cabo en su obra: un castellano andino, con numerosos préstamos léxicos del aymara y del quechua, y algunas marcas morfológicas y sintácticas procedentes de estos idiomas. Para defender esta forma expresiva utiliza un modo textual singular: la homilía. Pero si las homilías a las que el lector está acostumbrado elaboran desde el púlpito las nociones cristianas recibidas, la que nos presenta se realiza desde la perspectiva andina del Khori-Challwa, esto es, del Pez de oro, protagonista de la obra. Esta perspectiva es la que transforma el género en contra-discurso. ${ }^{1}$

\footnotetext{
${ }^{1}$ El uso a contra-corriente que hace Churata de la homilía puede conectarse con el empleo del sermón que Guaman Poma de Ayala realiza en El primer nueva corónica $y$ buen gobierno, y que Rolena Adorno ha subrayado: "Waman Puma aprovecha el discurso religioso cristiano creado para la autorreflexión espiritual y moral de los andinos y lo recrea colocando este espejo frente a los mismos europeos" (ADORNO, 1987, p. XXXI).
} 
Churata construye su argumentación polémica a partir de enunciados que la crítica del momento manejaba, pero excediéndolos o invirtiendo su sentido. Es el caso de la comparación entre los cronistas Garcilaso de la Vega y Guaman Poma, que ya aparecía en las tempranas recensiones de la crónica indígena realizadas por Richard Pietschmann, José de la Riva-Agüero y Raúl Porras Barrenechea (MONASTERIOS, 2015, p. 298-299). La otra idea que Churata lleva al extremo es la definición lingüística de la literatura americana. Churata se abandera de su lengua híbrida y se posiciona contra una crítica literaria que naturaliza el español para la literatura hispanoamericana, borrando cualquier referencia a las culturas indígenas de América. De esta manera, si el español es la lengua de la literatura americana, la literatura americana deviene una rama de la española. La idea la toma Churata del crítico hispanizante José de la Riva-Agüero que, como señala Mabel Moraña (2015, p. 157), la había expuesto en Carácter de la literatura del Perú independiente en 1905. Churata, con ese argumento llevado al extremo, llega a cuestionar obras consagradas, que había apreciado en la época de la revista Boletín Titikaka (1926-1930), como Don Segundo Sombra, de Ricardo Güiraldes, o Los de abajo, de Mariano Azuela. Hay, por tanto, una voluntad de perturbar el consenso crítico, que en los años cincuenta ya había establecido claramente un canon para la literatura hispanoamericana, y de poner de relieve la cuestión de la definición (o definiciones) de la literatura americana.

Para construir esta polémica, la oposición entre el Inca Garcilaso de la Vega y Guaman Poma de Ayala es estratégica. Cada uno de ellos encarna una "posibilidad" para la literatura americana, además de una tercera, representada por el Ollantay (CHURATA, 2012, p. 178). La que le atribuye al Inca Garcilaso es la hispanizante, pues, según Churata, Garcilaso abdica del quechua y en él "contienden los gérmenes indoespañoles con evidente subalternidad de 'lo indio', lo que a no poco constituiría la encrucijada del mestizo" (CHURATA, 2012, p. 162). Churata cita hasta tres veces las "Advertencias" del Inca Garcilaso para resaltar la importancia que el autor cuzqueño le da al quechua, pero reprochándole su abandono: "pues la manera señoril de advertir a España de las galanuras de su madre, era escribir en su lengua, que es melodiosa y fina, según él como pocos la encarece" (CHURATA, 2012, p. 154). En su lugar, el Inca Garcilaso adoptó el castellano que practicaría con riqueza y gracia, y, en consonancia, partió a España: 
se quedó en Córdova, revelando sólo que la primera naturaleza del injerto no habría de ser tanto el esteta como el pongo, el portero de la casa señorial en quien los señores no tuvieron albardero sino al simio antropomorfo que por esos días los naturalistas exhibían como antecesor del hombre. Al prestar pongueaje al Rey de España se marchara a las Cortes echando al desgaire el solar nativo con actitud que no explican y mal encubren sus reiteradas nostalgias y su no muy simpática quejumbre. (CHURATA, 2012, p. 156)

En estos reproches a Garcilaso vemos mucho más que una apreciación de su obra. Las referencias a la subalternidad a que son sometidos los indios, a su destino como empleados bajos (el pongo) y al racismo establecido científicamente constituyen un cuestionamiento radical de la sociedad peruana. Garcilaso es tratado como un símbolo de una configuración nacional que tiene en el mestizaje su emblema, pero que a pesar de su retórica de conciliación de razas, excluye al indígena de la ciudadanía. Como señala Paola Mancosu (2017, p. 446) “es necesario profundizar la articulación de la construcción de la nación peruana, que en cierto momento ha tomado al Inca como paradigma de referencia, y la lectura que Churata hace de él y de su obra".

En el campo literario, críticos como José de la Riva-Agüero concedieron a Garcilaso ese valor simbólico al presentarlo en su famoso discurso "Elogio del Inca Garcilaso" de 1916 como "el más perfecto representante y la más palmaria demostración del tipo literario peruano. Un mestizo cuzqueño, nacido al siguiente día de la Conquista, primero y superior ejemplar de la aleación de espíritus que constituye el peruanismo" (RIVA-AGÜERO, 1962, p. 57). Pero esta figura, emblema de la literatura nacional, a pesar de "los innegables atavismos indígenas" que el crítico le atribuye, es fundamentalmente hispánica. Para Riva-Agüero (1905, p. 227) las culturas indígenas habían sido "extinguidas", como afirmaba claramente en Carácter de la literatura del Perú independiente.

Esta exclusión (literaria, pero también cultural y social) es la que enfrenta Gamaliel Churata alzando contra el Inca Garcilaso la figura de Guaman Poma de Ayala (2012, p. 163). Gamaliel Churata demuestra el entusiasmo del descubrimiento de la crónica de Guaman Poma a la que tuvo acceso en la edición de 1941 que Arthur Posnansky publicó 
La Paz, donde Churata residía. ${ }^{2}$ Para él esta crónica indígena constituye un modelo de escritura, próximo a las formas vanguardistas que había practicado en los años veinte. En la recensión de su trayectoria en el artículo "Periodismo y Barbarie" de 1950 comenta: "Yo, con pleno derecho terrígena, aunque sin medios capaces, pretendí cierta vez aymarizar al español, como Huamán Poma de Ayala lo había keshwisado en su 'Coronica' y escribí hasta dos trabajos que publicara Mariátegui en 'Amauta' y Guillermo Guevara en 'La Sierra', ambas revistas limeñas de intención indigenista" (CHURATA, 2017, p. 183). De esta manera, la crónica de Guaman Poma le sirve como defensa de la forma de expresión del El pez de oro y como un modelo de inclusión del componente indígena en el entramado literario y social de los países andinos. En la "Homilía" de El pez de oro lo afirma rotundamente: "si América es una realidad genéticamente mestiza, la literatura americana debe ser idiomáticamente híbrida" (CHURATA, 2012, p. 165).

Como señalé, en este embate entre los dos cronistas, Churata cuestiona no solamente las formas de la literatura peruana, sino las de la americana señalándole tres posibilidades: "En tal punto el alud volcánico se dirige a la posibilidad Garcilazo, la posibilidad Huaman Poma o la posibilidad 'Ollantay'. Si Huaman nos da el diapasón, nada tenemos que acometer que no sea jerarquizar el español híbrido que hablan nuestros pueblos; si lo tercero..." (CHURATA, 2012, p. 178). Lo tercero significaría incluir en la literatura americana las obras escritas en lenguas indígenas: "Una posibilidad de literatura americana quedaría resuelta (se entiende que para el área del Tawantinsuyu) si los escritores americanos pudiesen emplear el aymara y el kheswa" (CHURATA, 2012, p. 184). Churata procura una ampliación de las formas de entender la literatura en América, incluyendo las lenguas indígenas y cuestionando la unicidad hispánica con la que se la caracterizaba en la época.

Para ello, como buen polemista, manipula y extrema el argumento de Riva-Agüero: si el idioma es lo que caracteriza a una literatura, y en español está escrita la americana, al modo de Garcilaso, sus obras pertenecen en consecuencia a la literatura española, desde las

\footnotetext{
${ }^{2}$ Gamaliel Churata partió al exilio en Bolivia en 1932 y permaneció en La Paz hasta 1964. Durante su estancia en Bolivia, Arthur Posnansky publicó la obra de Guaman Poma, primero en 1941 en los números 63-66 del Boletín de la Sociedad Geográfica de La Paz y en 1944 en un solo volumen (MONASTERIOS, 2015, p. 297).
} 
de Rubén Darío y Leopoldo Lugones a las de Mariano Azuela y Ciro Alegría (CHURATA, 2012, p. 178-179). La posibilidad que personifica el Inca Garcilaso remite a las formas establecidas de la literatura hispanoamericana del momento, contra las que Churata se posiciona para intentar entrever otras formas de entender la literatura, entre ellas, la que él mismo practica. Contra este canon, postula otros nombres como los de Jorge Icaza, José María Arguedas y Luis Cardoza y Aragón (CHURATA, 2012, p. 182).

Queda claro, pues, que la polémica no se centra tanto en las obras del Inca Garcilaso de la Vega y de Guaman Poma, sino en lo que representarían, como formas diversas de la escritura americana y, también, de un programa político de asimilación o de reconocimiento de la ciudadanía indígena. En ese sentido, Churata realiza una operación anacrónica, atribuyendo a los autores del siglo XVII los discursos que la interpretación de su obra generaría. Por ello, la crítica no es contra el Inca Garcilaso, sino contra la instrumentalización de su figura por parte de un sector social hispanizante. Esto explica que en El pez de oro los dos cronistas sean estimados como fuente y que en otros ensayos aparezcan juntos y valorados positivamente. Más aún, de Garcilaso Churata toma muchas estrategias que le sirven para cuestionar el hispanismo peruano y avanzar en el reconocimiento de las culturas andinas. Para demostrar esta lectura de los dos cronistas por parte de Gamaliel Churata en El pez de oro a continuación voy a desarrollar tres temas centrales de la obra en los que ambos están muy presentes.

\section{La lengua}

Como fue señalado, en $\mathrm{El} \mathrm{pez} \mathrm{de} \mathrm{oro} \mathrm{una} \mathrm{de} \mathrm{las} \mathrm{cuestiones}$ principales es la lengua. Además de ser el medio expresivo, en una intención de transformación del lenguaje fiel al impulso vanguardista de los años veinte (SCHWARTZ, 1995), su uso de la lengua condensa el objetivo mayor de Churata de imaginar un mundo andino en que los elementos culturales indígenas e hispanos se encuentren imbricados. Para el autor, la lengua sostiene ese mundo y por ello es el motivo principal de la polémica reseñada anteriormente. Churata reivindica la presencia activa de las culturas andinas en la literatura desde el entramado lingüístico de estas. La textura de las obras - el textil andino como modelo de producción cultural está muy presente en la obra de 
Churata (MARSAL, 2015) - debe mostrar la pluralidad cultural donde nace esa literatura.

A pesar de la polémica trazada en las primeras páginas de $E l$ pez de oro, los Comentarios Reales del Inca Garcilaso también van en esa dirección y constituyen un modelo para Churata. El inca Garcilaso fundamenta su obra, como Churata, en la presencia de la lengua general o runasimi. Es lo que lo distingue de los otros cronistas y le permite reparar sus errores:

En el discurso de la historia protestamos la verdad de ella y que no diremos cosa grande que no sea autorizándola con los mismos historiadores españoles que la tocaron en parte o en todo. Que mi intención no es contradecirles sino servirles de comento y glosa y de intérprete en muchos vocablos indios que, como extranjeros en aquella lengua, interpretaron fuera de la propiedad de ella según que largamente se verá en el discurso de la historia. (GARCILASO DE LA VEGA, 1991, p. 4)

La corrección de la lengua importa mucho, pues la lengua constituye para él "una herramienta de carácter hermenéutico al servicio de la verdad histórica" (CERRÓN-PALOMINO, 1993, p. 220). Garcilaso escribe, en una intención semejante a la de Churata, para inscribir y asegurar la permanencia del mundo andino, y para ello debe reparar la lengua, deturpada sistemáticamente por los españoles. En ese sentido, Garcilaso transmite una versión de la tensión cultural entre españoles e indígenas que es una tensión lingüística, donde la violencia de la conquista se revela en la incapacidad del comprender al otro y en la sistemática imposición de palabras ajenas.

Garcilaso actúa como intérprete, orgulloso de una lengua y tradición que "mamó en la leche" (GARCILASO DE LA VEGA, 1991, p. 94). Como señala Mercedes Serna, se trata de una actitud que Garcilaso fundamentó en su formación humanística, y que desplegó en su primera obra, precisamente una traducción:

Ya en los Diálogos de amor aparece la idea clave que va a hacer del Inca Garcilaso un escritor de ánimo reivindicativo: convertirse en un intérprete (traductor, reformador, comentador, restañador, rectificador, ampliador) lingüístico y, por tanto, histórico, cultural y espiritual, absolutamente fidedigno. La interpretación exacta de la palabra podrá modificar la historia. (SERNA, 2000, p. 26) 
Siguiendo el método filológico humanístico (SERNA, 2000, p. 28), las palabras que el Inca Garcilaso traduce son significativas culturalmente, términos clave sobre los que despliega su "capacidad metalingüística autorreflexiva" (CERRÓN-PALOMINO, 1993, p. 245). Son conceptos que configuran el espacio, la vida cotidiana, la historia, la economía, el pensamiento o los mitos. Como señala Rodolfo CerrónPalomino (1993, p. 245), Garcilaso nos ofrece en algunos casos, como en el que hace referencia a procesos de lexicalización, "una categorización semántica del mundo andino", que "refleja, en el orden cultural, la manera distinta en que la mentalidad andina organiza, categoriza y nombra el mundo de su experiencia circundante, tanto en sus manifestaciones físiconaturales como humanas y sociales" (CERRÓN-PALOMINO,1993, p. 248). Garcilaso se niega a la tabula rasa de su cultura decretada por RivaAgüero y hace un compendio conceptual del que Churata toma mucho.

También Churata utiliza un procedimiento semejante al incluir en su texto palabras en aymara o quechua, que él llama "incrustaciones indias" (CHURATA, 2012, p. 167), y que en su nota inicial define como "formas orgánicas en que el barbarismo indígena pretende consolidar una retórica naturaleza. De estas formas se esperdigan a lo largo del libro, aun entre el discurso hispánico del relato; y es necesario señalarlas, no confundirlas, sobre todo, como solecismos, para establecer su acaso única originalidad" (CHURATA, 2012, p. 148). Por tanto, en estas incrustaciones, o términos clave, radicaría para Churata la singularidad de su obra. La diferencia con Garcilaso es que Churata las inserta en el texto sin traducción, elaborando un discurso híbrido en el que las palabras andinas entran en la trama hispánica, como la urdimbre de un tejido. Sin embargo, Churata no deja de trazar los puentes de la comunicación, y al final de su obra incluye un glosario donde elabora definiciones muy personales de los términos aymaras y quechuas.

Si la traducción es la principal estrategia a la que recurre el Inca Garcilaso, realizando una mediación entre ambos universos lingüísticos "para que allá y acá se entiendan" (GARCILASO DE LA VEGA, 1991, p. 526), Guaman Poma incorpora directamente el quechua a su discurso. La de Guaman Poma representaría para Churata la lengua que está buscando, donde el quechua y las otras lenguas andinas no aparecen como término a ser traducido, sino en continuidad con el castellano. Por ello, hay largos fragmentos sin traducción que demuestran la confianza en un lector indígena, al que se dirige en muchos momentos directamente. 
De esta manera, en la crónica de Guaman Poma hay inscritos varios destinatarios, no solo el rey Felipe III y el Papa, sino que el autor aspira a que su obra regrese de España impresa y sea divulgada entre españoles e indios (GUAMAN POMA DE AYALA, 2005, p. 17-18). Como señala Mercedes López-Baralt (2005, p. 163), "la Nueva coronica está dirigida a toda la sociedad virreinal, a cada uno de sus lectores u oidores apostrofará al autor desde sus 'prólogos', para conminarlos a vivir el buen gobierno". Eso es lo que debió entusiasmar a Churata: la capacidad de desplegar distintos códigos simultáneamente, dirigidos a interlocutores diversos, para expresar su mensaje. En ella encontramos varias lenguas, varios mundos conceptuales y varios sistemas semióticos. Otra cuestión importante para Churata es el lugar de enunciación, que en Guaman Poma no es hispánico, sino claramente indígena: el sistema colonial es descrito con los ojos orgullosos del letrado indígena que desde su ascendencia noble se inserta en él y lucha por modificarlo. Guaman Poma parece ofrecer la historia vista desde el otro lado, y esta operación de inversión de perspectivas es la que procura Churata en $E l$ pez de oro. Julio Ortega señala que escribir desde el quechua comporta este giro conceptual:

Guaman Poma se dirige al rey Felipe III para persuadirlo de reformar la empresa colonial y para aconsejarle sobre la suerte de las Indias; pero la fuente de su información, siendo, en buena parte, producto de crónicas, relaciones y repertorios de la evangelización, tiene como modelo el orden natural del mundo aborigen, cuya formalidad es el quechua. [...] el discurso es una suerte de máquina de la memoria (porque preserva los órdenes de la cultura nativa, la lógica de su sentido), pero también es un instrumento mediador que transforma el dato occidental en dato aborigen para, en seguida, presentar el dato aborigen en su propia racionalidad y dentro del nuevo orden del mundo cristianoespañol. De ese modo, la cultura se preserva, desde el quechua, gracias a la lengua española. (ORTEGA, 1988, p. 366)

La propia figura del intelectual indígena que Guaman Poma encarna es la que Churata defiende durante toda su trayectoria periodística y literaria. En El primer nueva corónica y buen gobierno de Guaman Poma aparecen además de él varios personajes capaces de reclamar sus derechos desde las estrategias letradas, como su discípulo don Cristóbal de León(GUAMAN POMADE AYALA, 2005, p. 383; 552), perseguidos 
por las autoridades coloniales: "Que los dichos corregidores y padres $\mathrm{y}$ encomenderos quieren muy mal a los indios ladinos que saben leer y escribir, y más si saben hacer peticiones por que no le pidan en la residencia de todo los agravios y males y daños; y, si pueden, le destierra del dicho pueblo en este reino" (GUAMAN POMA DE AYALA, 2005, p. 747). A pesar de ello, recomienda la necesidad de instituir escuelas para indios e indias, para que puedan conocer los códigos de la nueva sociedad y defenderse: "Que en este reino en los pueblos chicos o grandes haya escuela y sepan leer y escribir, cantar canto de órgano, los dichos niños y niñas todos" (GUAMAN POMA DE AYALA, 2005, p. 547). Esta agencia indígena, $\tan$ poco visible desde la perspectiva occidental, que supera el indigenismo paternalista de inicios del siglo XX, pues surge de los propios intereses indígenas, es la que dinamiza Churata, sobre todo en la época del Boletín Titikaka (MONASTERIOS, 2015, p. 194). En una conferencia que dio en 1966 en la Universidad Nacional Federico Villarreal, Churata señala al recordar el grupo Orkopata:

Orkopata fue la universidad de una generación. Allí en Orkopata, vivíamos, pensábamos y escribíamos con los indios y en indio [...] Al lado de los poetas que hemos nombrado, vivían generaciones de indios que yo, al retornar al país después de tres décadas de ausencia, he encontrado convertidos en periodistas, en industriales, en hombres de gran personalidad. (CHURATA, 1989, p. 65)

La cuestión que Churata más resalta es que Guaman Poma escribe su castellano desde el quechua y en él aparecen las marcas de ese origen: lengua aprendida desde lo indígena, que muestra su perspectiva y que la incorpora al castellano, en una hibridez que transforma la lengua de la metrópolis. También lengua que grita, que llora, que se indigna, lengua crítica al fin; López-Baralt habla de la "retórica del grito" en Guaman Poma (2005, p. 191). Ese sería el modelo con el que se identifica Churata y que asume en El Pez de oro. Lo que Gamaliel Churata busca reivindicar, lingüística y literariamente, es un entramado cultural donde lo indígena no se encuentre en posición de subalternidad, sino que en una posición horizontal genere una tensión con lo hispánico. Por ello, Churata busca destacar el desorden que el quechua provoca en el castellano de Guaman Poma. De esta manera, toma a su favor las acusaciones de mala escritura que algunos críticos, como José de la Riva-Agüero (1962, p. 50), 
señalaron contra el cronista, pues ella revelaría "el proceso de hibridación idiomática que sería lo más vivaz de la resistencia india frente al dominio hispano" (CHURATA, 2012, p. 165).

Este "encuentro" de lenguas distintas que se superponen, que Churata busca incorporar a su obra, puede relacionarse con el modelo andino de la tensión de los contrarios, como ha sido señalado por Miguel Ángel Huamán (1994, p. 64): "El tinkuy es la zona de encuentro donde se juntan dos elementos que proceden de dos direcciones diferentes, permite realizar el ideal de unidad o de las cosas que siempre vienen juntas (yanatin) como dos ojos, dos manos, etc.; mitades perfectas de un centro primordial o taypi. Este es el género del Pez de oro". Como recuerda Mercedes López-Baralt (2005, p. 126-127; 176-177), el propio Garcilaso nos da noticia de este sistema de organización conceptual en el capítulo XVI de su crónica al describir la fundación del Cuzco en dos mitades. López-Baralt (2005, p. 127) vincula este sistema al tinku, ${ }^{3}$ que define del siguiente modo: "aún hoy las comunidades indígenas del Perú se escinden en estas dos mitades, que se unen ritualmente en un tinku, encuentro periódico, a veces violento, que expresa simbólicamente la conflictiva totalidad que constituye el grupo social".

Pero Garcilaso en su obra, desde su práctica de la traducción, vela el conflicto y acerca este modelo andino al ideal humanístico de la concordia aprendido en León Hebreo, que Cornejo Polar caracterizó como "discurso de la armonía imposible": "el discurso garcilasista deja constancia de lo indio y lo español pero inmediatamente insume a ambos, desconflictivizando su mutua alteridad, en una complaciente categoría totalizadora. En cierto sentido la producción verbal de la sinonimia disuelve la dualidad de las miradas que están en su origen" (CORNEJO POLAR, 2003, p. 87). Tanto en Garcilaso como en Churata la lengua representa un puente necesario entre las culturas. Pero mientras "Garcilaso utiliza la lengua para tratar de armonizar ambas culturas siguiendo el ideal renacentista de concordia y de conciliación de los

\footnotetext{
${ }^{3}$ También Luis Millones observa el tinkuy en las obras de Guaman Poma y de Garcilaso y lo define como tensión de contrarios: "El hecho que el tinkuy reúna ambos conceptos: unión y lucha, contribuye a la interpretación de encuentro en contexto de violencia que propongo para las escenas descritas. La unión es, vale recordarlo, una unión de contrarios que no podemos imaginar sino como un momento de concentración de fuerzas opuestas".
} 
opuestos" (SERNA, 2000, p. 45), y consigue un castellano de gran calidad literaria, con su abertura al otro a partir de la traducción, lo que le da incuestionablemente un espacio en composición subordinada, Churata opta por una lengua intencionadamente inarmónica, que muestre el conflicto y a los dos componentes culturales en yuxtaposición.

Finalmente, la propia naturaleza de la lengua queda en entredicho. Como es sabido, junto a su texto Guaman Poma incorpora cerca de 400 dibujos que van más allá de la ilustración. Con ellos, el género adoptado, la crónica, como modelo hispánico de inscripción en la realidad, es profundamente alterado. Como señala Antonio Cornejo-Polar (1982, p.77), "los dibujos de Guamán Poma dicen mucho más sobre el mundo andino que el español rudimentario con que está escrita la Nueva Crónica... y su sola presencia indica la acción de una dinámica inversa: si en otros casos el proceso productivo sofocaba el referente, en éste, al contrario, el referente puede imponer ciertas condiciones y generar una modificación en la estructura formal de las crónicas". Rolena Adorno describe el simbolismo espacial andino que subyace en los dibujos de Guaman Poma con la convicción de que "the arrangement of icons in space allows for an additional visual interpretation and is responsible for an additional level of pictorial meaning. Thus, although pictorially expressing himself in ways that are comprehensible to the European reader, Guaman Poma employs and remains true to his own autochthonous values of symbolic representation" (ADORNO, 2000, p. 89).

Antonio Cornejo Polar vio con lucidez el desafío que constituía para la crítica asumir este tipo de discursos heterogéneos, de procedencia indígena o popular, no consagrados por la historiografía literaria dominante: "En esta ampliación del corpus, que de inmediato convierte en multilingüe la literatura colonial, la articula bajo el doble modelo de la escritura y la oralidad, con sus zonas de repulsión y confluencia, y la refiere a una constelación de conciencias sociales disímiles y, al mismo tiempo, entreveradas, está en debate la propia noción de literatura" (CORNEJO POLAR, 1994, p. 367-368). Si la letra fue identificada desde el inicio de la presencia española "no tanto como un sistema de comunicación, sino en el horizonte del orden y la autoridad, casi como si su único significado posible fuese el Poder" (CORNEJO POLAR, 1990, p. 169), las prácticas de resistencia cultivaron y desarrollaron otras formas de expresión para la comunión y el disentimiento, como las fiestas, las imágenes, la música, las canciones, las danzas, las leyendas o los cuentos. 
Este desafío mayor de abrirse a prácticas discursivas no alfabéticas es asumido por Churata, que parte de las fiestas, la danza, el canto y el tejido para construir su obra. En última instancia, este gesto constituye un cuestionamiento de la compresión occidental de la propia literatura y su validez universal (NATALI, 2006). Mientras la filología humanística del Inca Garcilaso privilegia una definición alfabética del conocimiento, al cual traduce las formas culturales del mundo inca, Churata, como Guaman Poma, asume diversos medios expresivos andinos y cuestiona, estructuralmente en El pez de oro, y discursivamente en Resurrección de los muertos, el supuesto privilegio del "hombre-letra".

\section{El mestizaje}

Como se ha señalado, Churata (2012, p. 165) propone un modelo de lengua que reconozca el mestizaje que conforma la sociedad americana: "si América es una realidad genéticamente mestiza, la literatura americana debe ser idiomáticamente híbrida". Él mismo se identifica como un mestizo al que le fue sustraída su lengua materna: "los mismos que apenas la sentimos [a la lengua quechua] en el gusto a saliva onírica, comprobamos cómo es ella lo que se nos amputó del alma sabiendo que así se nos privaría de una maternidad idiomática" (CHURATA, 2012, p. 155). Frente a ello, Churata propone la recuperación de ese componente cultural perdido, en una definición del mestizaje que resulta el reverso del que se imponía en la época, pues Churata defiende un mestizaje que parta del componente indígena: "se puebla el continente de individuos que representan fundidas en matriz aborigen todas las razas humanas" (CHURATA, 2004, n. 22). ${ }^{4}$

Con esta propuesta, que Churata lanza en el artículo titulado "Indoamericanismo", publicado en el Boletín Titikaka en febrero de 1928, se enfrenta a otras concepciones del momento, en especial a la que José Vasconcelos había formulado en 1925 en La raza cósmica, donde describe una nueva raza, que surgiría del mestizaje de las otras razas del planeta (VASCONCELOS, 1982). Si bien esta noción cuestiona las pretendidas razas puras que subordinan a las demás, el mestizaje

\footnotetext{
${ }^{4}$ La edición facsimilar del Boletín Titikaka utilizada para elaborar este trabajo carece de paginación. Por ello, en la referencia señalo el número de la revista en que el artículo aparece.
} 
vasconcelista promueve una homogeneización cultural de base hispánica. Esta convicción se traduce en una cancelación de las culturas indígenas: "Los mismos indios puros están españolizados, están latinizados, como está latinizado el ambiente. Dígase lo que se quiera, los rojos, los ilustres atlantes de quienes viene el indio, se durmieron hace millares de años para no despertar" (VASCONCELOS, 1982, p. 24). De ahí que Vasconcelos (1982, p. 25) decrete la asimilación como única forma de modernidad: "El indio no tiene otra puerta hacia el porvenir que la puerta de la cultura moderna, ni otro camino que el camino ya desbrozado de la civilización latina".

Gamaliel Churata se opone a este dictamen y defiende durante toda su acción política y cultural la pervivencia de las culturas andinas. EL pez de oro es la prueba de ese diálogo entre los diversos componentes culturales del Perú, donde lo indígena sigue muy presente. Si el mestizaje vasconcelista exalta la mezcla de lo diverso para reafirmar la mismidad occidental, el mestizaje de Churata propone un modelo autóctono.

En esta tensión la figura del Inca Garcilaso es ejemplar. Asume su condición de mestizo de forma orgullosa: "A los hijos de español y de india - o de indio y española - nos llaman mestizos, por decir que somos mezclados de ambas naciones. Fue impuesto por los primeros españoles que tuvieron hijos en Indias. Y por ser nombre impuesto por nuestros padres y por su significación me lo llamo yo a boca llena y me honro con él" (GARCILASO DE LA VEGA, 1991, p. 627). Pero, a la vez, junto con esta declaración, Garcilaso nunca deja de reivindicar su origen indígena, desde las "Advertencias" donde afirma rotundamente: "soy indio" (GARCILASO DE LA VEGA, 1991, p. 5). Constantemente encontramos en los Comentarios reales la identificación con su "tierra", su "patria", y menciones a la convivencia con su familia materna. Ese origen es clave en la obra pues es el que le autoriza a hablar y a corregir las obras de sus antecesores españoles: "yo, como indio que conocí la condición de los indios, osaré afirmar que pasó así" (GARCILASO DE LA VEGA, 1991, p. 503). El mestizaje deviene entonces una perspectiva de conocimiento, que permite el acceso a ambas culturas.

El mestizaje, al contrario, nunca será defendido por Guaman Poma. $\mathrm{Su}$ rechazo constituye una denuncia de la violencia y las violaciones sistemáticas que se ve forzado a relatar una y otra vez. Guaman Poma apela a las ordenanzas de Francisco de Toledo para recomendar mantener separados a los componentes sociales de la colonia, los indios en sus 
pueblos y los demás en las ciudades, sin mezclas (GUAMAN POMA DE AYALA, 2005, p. 343).

En Churata esta segregación es imposible. Lo occidental y lo andino entran en comunicación y dialogan constantemente. Lo que propone Churata es un mestizaje cultural que asuma el mundo y converse con él desde una identidad india, por tanto, propone una diversidad en diálogo y no una unicidad indígena. Pero Guaman Poma también se convierte en un modelo por el mestizaje cultural que ostenta, al construirse en su propia obra como un letrado indígena que sostiene ambos saberes, tanto el hispánico y católico de las autoridades a las que se dirige y pretende persuadir, como el de las culturas andinas. Como señala Rocío Quispe-Agnoli (2007, p. 418): "Estamos, además, ante un 'autor' que adquiere o confirma el poder y el saber-hacer empleando los elementos de dos códigos culturales diferentes. En este sentido, se trata de un sujeto híbrido que se posiciona entre dos culturas".

Churata lucha por un mestizaje al revés, ${ }^{5}$ hacia lo indígena, que se opone tanto a la hispanización forzosa que auguraba Vasconcelos como al aislamiento indígena de Guaman Poma. La noción del mestizaje de Churata es diversa de la expuesta en La raza cósmica, no sólo porque invierte el elemento que adquiere la preeminencia, sino también porque lo formula desde el pensamiento indígena. La noción de raza en Churata es ajena al biologismo positivista pues parte de otro principio: como fue señalado, es la noción andina de tinkuy, de la tensión permanente de los contrarios, la que anima este mestizaje que no significa fusión de los diversos componentes en un nuevo individuo, sino presencia contendiente de ambos:

El escritor mestizo balbuce lengua corrosiva que alimenta con vidas que son y no son suyas, constatando a diario que si entre España y América periclitaron pleitos, no pasa lo mismo con él, y que, o ahoga al indio, o expulsa al español. Allí donde todavía la contención exista, el drama del "pensamiento" americano se alimentará de ella; si es en ella que se originan sus pseudomorfosis psicopatológicas. Pero el vivir de América es perseguir la unidad en medio a la acción de polos igualmente compelentes: por un lado España; por otro la montaña indiática. (CHURATA, 2012, p. 199)

\footnotetext{
${ }^{5}$ Le agradezco a Elizabeth Monasterios el haber convocado esta idea en una conversación en Cagliari, en el marco del seminario de investigación "El planeta de los animales locos". Paisaje, naturaleza y ser humano en Gamaliel Churata".
} 
Por tanto, Churata no se limita a celebrar la mezcla racial como solución de los conflictos; el mestizaje es conflicto en sí, presencia constitutiva de varios aportes, que se asume como posibilidad americana al reunir tiempos y perspectivas: "el fatalismo de América es mantenerse presta a captar el mensaje del mundo - percibimos finamente dentro de nosotros mismos un vago ritmo en que renacen conciencias sepultas y germinan módulos futuros" (CHURATA, 2004, n. 22).

\section{La denuncia anticolonial}

Gamaliel Churata asume en El pez de oro la indignación de Guaman Poma, su crítica nada velada al sistema colonial y a la explotación a la que son sometidos los indios. La denuncia es sistemática, realizada por todos los medios, y casi no hay página en la extensa Primer nueva corónica $y$ buen gobierno que no constituya una protesta. Churata recupera su acusación sistemática, en nuevos escenarios donde, paradójicamente, a pesar de la Independencia, los abusos empeoran: "La Revolución de los Libertadores consagra el derecho de los encomenderos, y en el hecho, aunque no en la letra (coordenada típicamente criolla), pone punto final al del íncola"'(CHURATA, 2012, p. 197).

En el Inca Garcilaso la crítica está velada pero no ausente. La reconstrucción idealizada del mundo incaico como honesto y magnánimo conlleva el contraste con el presente injusto. Como señala Antonio Mazzotti (2016), Garcilaso sitúa la doctrina "bien común" de inspiración jesuita, como fundamento del gobierno incaico y también como proyecto político. Sin embargo, su disensión no puede enunciarse. Garcilaso deja explícita su imposibilidad de denuncia: "dirán que por ser indio hablo apasionadamente" (GARCILASO DE LA VEGA, 1991, p. 301). Mercedes López-Baralt señala la censura de la Inquisición (que ya había prohibido su traducción de los Diálogos de amor) como la responsable de estos silencios y operaciones de encubrimiento: "La censura le obliga a cuidar con denuedo todo lo que dice y a usar la entrelínea, los silencios, la ironía, a veces el halago... De ahí que no debamos dejarnos engañar por la serenidad con que Garcilaso concilia los opuestos; tras ella late un dolor muy intenso que aflora pudorosamente en sus páginas" (LÓPEZ-BARALT, 2005, p. 130). Precisamente Churata afirma en su artículo "El dolor americano" que desde Garcilaso la conciencia de la injusticia marca toda la literatura peruana, especialmente César Vallejo 
y Alejandro Peralta, en forma de dolor y desgarramiento: "Tornose en esclavitud nuestro señorío, decía, con esa tristeza ya jerarquizada el dulce y saudoso Inca Garcilazo de la Vega. Los wayñus y yaravíes del cholo o del indio han sido desde entonces, y como resultado de este proceso de inmersión de pueblo indio, nada más que pretextos para embellecer el dolor" (CHURATA, 2009, p. 137). Para Churata este dolor es el síntoma de una vida que permanece: “¿Si lo que más duele de América es el indio, será porque está muerto? No parece. Si el indio nos duele es porque nada hay más vivo en nosotros que el indio. Y si nada en el indio duele más que América, será porque sólo en el indio América está viva" (CHURATA, 2012, p. 343).

\section{Conclusiones}

En este recorrido por algunos de los temas principales que desarrolla Gamaliel Churata queda claro cómo Garcilaso y Guaman Poma aportan componentes fundamentales de El pez de oro. La denuncia al sistema colonial, así como la reivindicación de la cultura andina, vinculan a estos autores con el propósito anticolonial de Churata, que se enfrenta a la crítica literaria hispanoamericana y al imaginario social que sustenta para reprocharle su injusticia. Este gesto es reivindicado por la crítica postcolonial contemporánea por su necesaria beligerancia y actualidad.

\section{Referencias}

ADORNO, R. Guaman Poma. Writing and Resistance in Colonial Peru. Austin: University of Texas Press, 2000.

ADORNO, R. Waman Puma: el autor y su obra. In: GUAMAN POMA DE AYALA, F. Nueva crónica y buen gobierno. Madrid: Historia16, 1987. p. XVII-XLVII.

CALlO CUNO, D. (Ed.). Boletín Titikaka. Arequipa: Universidad Nacional de San Agustín, 2004. No paginado. Edición facsimilada,

CERRÓN-PALOMINO, R. Los fragmentos de gramática quechua del Inca Garcilaso. Lexis, Lima, v. 17, n. 2, p. 219-257, 1993. 
CHURATA, G. Conferencia en la Universidad Federico Villarreal. In: MOROTE GAMBOA, G. (Ed). Motivaciones del escritor: Arguedas, Alegría, Izquierdo Ríos, Churata. Lima: Universidad Nacional Federico Villarreal, 1989. p. 59-67.

CHURATA, G. El dolor americano. In: GONZALES FERNÁNDEZ, G. (Ed.). El dolor americano: literatura y periodismo en Gamaliel Churata. Lima: Fondo Editorial del Pedagógico San Marcos, 2009. p. 137-140.

CHURATA, G. El pez de oro. Edición de Helena Usandizaga. Madrid: Cátedra, 2012.

CHURATA, G. Indoamericanismo. In: CALLO CUNO, D. (Ed.). Boletin Titikaka. Arequipa: Universidad Nacional de San Agustín, 2004. No paginado. Edición facsimilada.

CHURATA, G. Textos esenciales. Edición de Wilmer Kutipa. Tacna: Perro calato, 2017.

CORNEJO POLAR, A. Los discursos coloniales y la formación de la literatura hispano-americana (reflexiones sobre el caso andino). In: MARCO, J. (Coord.). Actas de XXIX Congreso del Instituto Internacional de Literatura Iberoamericana. Barcelona: PPU, 1994. v. 1.

CORNEJO POLAR, A. El comienzo de la heterogeneidad en las literaturas andinas: voz y letra en el "diálogo" de Cajamarca. Revista de Crítica Literaria Latinoamericana, Lima, año XVII, n. 33, p. 155-207, 1990.

CORNEJO POLAR, A. El indigenismo y las literaturas heterogéneas: su doble estatuto sociocultural. In: . Sobre literatura y crítica latinoamericanas. Caracas: Universidad Central de Venezuela, 1982. p. 67-85.

CORNEJO POLAR, A. Escribir en el aire: ensayo sobre la heterogeneidad socio-cultural en las literaturas andinas. Lima: CELACP, Latinoamericana Editores, 2003.

CORNEJO POLAR, A. Heterogeneidad y contradicción en la literatura andina: tres incidentes en la contienda entre oralidad y escritura. Nuevo Texto Crítico, Stanford, año V, n. 9/10, p. 103-111, 1992.

GARCILASO DE LA VEGA, I. Comentarios reales de los incas. Edición de Carlos Araníbar. Lima: FCE, 1991. 2 v. 
GUAMAN POMA DE AYALA, F. Nueva corónica y buen gobierno. Edición de Franklin Pease. Lima: FCE, 2005.

HUAMÁN, M. A. Fronteras de la escritura: discurso y utopía en Churata. Lima: Horizonte, 1994.

LÓPEZ-BARALT, M. Para decir al otro: literatura y antropología en nuestra América. Madrid: Iberoamericana; Frankfurt am Main: Vervuert, 2005.

MANCOSU, P. El Inca Garcilaso: una lectura de Gamaliel Churata. Revista de Crítica Literaria Latinoamericana, Boston, año XLIII, n. 85, p. 445-468, 2017.

MARSAL, M. H. Tramas transandinas. Dinámicas culturales del textil andino. Revista Iberoamericana, Pittsburgh, v. LXXXI, n. 253, p. 10431060, 2015.

MAZZOTTI, A. El inca Garcilaso en el siglo XXI: pensamiento político y nuevas pistas para una agenda latinoamericana. Casa de las Américas, La Habana, n. 283, p. 3-15, 2016.

MILLONES, L. El encuentro o "tinkuy" en textos coloniales andinos. [s.n.t]. Disponible en: $<$ https://sites.fas.harvard.edu/ icop/luismillones. html>. Acceso en: 19 nov. 2018.

MONASTERIOS, E. La vanguardia plebeya del Titikaka: Gamaliel Churata y otras beligerancias en los Andes. La Paz: IFEA, Plural, 2015.

MORAÑA, M. Churata postcolonial. Lima: Latinoamericana Editores, CELACP, 2015.

NATALI, M. Além da literatura. Literatura e Sociedade, São Paulo, v. 11, n. 9, p. 30-43, 2006. doi: https://doi.org/10.11606/issn.2237-1184. v0i9p30-43

ORTEGA, J. El cronista indio Guaman Poma de Ayala y la consciencia cultural pluralista en el Perú colonial. Nueva Revista de Filología Hispánica, México, t. 36, n. 1, p. 365-377, 1988.

QUISPE-AGNOLI, R. Prácticas indígenas de la resistencia: sujetos de la escritura y el saber en los Andes coloniales. Revista Iberoamericana, Pittsburgh, v. LXXIII, n. 220, p. 415-436, 2007. doi: https://doi. org/10.5195/REVIBEROAMER.2007.5336 
RIVA-AGÜERO, J. Carácter de la literatura del Perú independiente. Lima: Editorial Rosay, 1905.

RIVA-AGÜERO, J. Estudios de literatura peruana: del inca Garcilaso a Eguren. Lima: Pontificia Universidad Católica del Perú, 1962. (Obras Completas de José de la Riva-Agüero, II).

SCHWARTZ, J. Lenguajes utópicos. "Nwestra ortografia bangwardista": tradición y ruptura en los proyectos lingüísticos de los años veinte. In: PIZARRO, A. (Org.). América Latina: Palavra, literatura e cultura. São Paulo: Memorial; Campinas, UNICAMP, 1995. v. 3, p. 31-55.

SERNA, M. Introducción. In: GARCILASO DE LA VEGA, I. Comentarios reales. Edición de Mercedes Serna. Madrid: Castalia, 2000. p. 9-81.

USANDIZAGA, H. Introducción. In: CHURATA, G. El pez de oro. Edición de Helena Usandizaga. Madrid: Cátedra, 2012. p. 11-143.

VASCONCELOS, J. La raza cósmica. México: Espasa-Calpe, 1982.

Recebido em: 25 de junho de 2018. Aprovado em: 23 de outubro de 2018. 